\title{
COORDINATION OF LARGE PULSED LOADS ON FUTURE ELECTRIC SHIPS
}

\author{
By: \\ L.N. Domaschk \\ A. Ouroua \\ R.E. Hebner \\ O.E. Bowlin \\ W.B. Colson
}

13th Electromagnetic Launch Technology Symposium, Potsdam (Berlin), Germany, May 22-25, 2006

IEEE Transactions on Magnetics, Vol. 43, No. 1, January 2007, pp. 450-455.

PR 404

Center for Electromechanics

The University of Texas at Austin

PRC, Mail Code R7000

Austin, TX 78712

(512) 471-4496 


\title{
Coordination of Large Pulsed Loads on Future Electric Ships
}

\author{
Lori N. Domaschk, Abdelhamid Ouroua, and Robert E. Hebner \\ Center for Electromechanics \\ University of Texas at Austin, Texas, U.S.A. \\ Oscar E. Bowlin and W. B. Colson \\ Naval Postgraduate School, Monterey, California, U.S.A.
}

\begin{abstract}
Part of the technical versatility of future all-electric ships is the potential ability to share large amounts of power among a variety of high power loads. To help evaluate this potential and to provide information to help guide technology selection, a physics-based model of a power train for an electric ship has been developed and implemented on three modeling platforms. Using this model, three different investigations have been carried out to explore aspects of the behavior of a rotating machine power source for a shipboard rail launcher. These were 1) influence of rapid charging of the rotating machine system on the ship power system, 2) use of the stored energy in the rotating machines to improve ship power quality, and 3) use of the stored energy in the rotating machines to power a pulsed free-electron laser.
\end{abstract}

Each study highlighted different integration opportunities and challenges. The first showed that, because the charging of the rail launchers was through $5 \mathrm{MW}$ motors, there could be a voltage sag for a few cycles, but this could easily be managed so that the sag could be reduced to an inconsequential level. The second study showed that, with appropriate power electronics, the stored energy in the rail launcher power supply can be used to correct power quality problems introduced by other ship systems. Finally, the stored energy in the launcher power supply can be used to fire a free electron laser for ship defense. This feature opens the possibility of routine operation of the entire ship at highest efficiency, i.e., with the smallest number of gas turbines operating near full power, while providing stored energy needed for ship defense.

\section{INTRODUCTION}

An advantage of electric warships is that they carry sufficient electric power generation capability to make new types of systems feasible. These new systems use electric power rather than chemical propellants, providing for a safer ship, reduced logistics, and systems more appropriate to the tempo and nature of anticipated future 
conflicts than conventional systems. A challenge, however, is the integration of these new systems with the power systems on electric ships.

One key element is the integration of large pulsed loads with the steady-state loads while maintaining power quality so that the sensitive loads continue to operate unperturbed. It is clear that some combination of onboard storage and the exploitation of the ship's momentum to divert propulsion power for pulsed applications should provide power system designs that yield minimum weight and volume and yet supply all anticipated loads. While the system is not sufficiently defined to permit formal minimization of the weight and volume, it is important, at this stage of development, to examine potential synergies among the various subsystems to help guide the development process. This paper extends earlier work [1], [2] to show that the energy stored in the alternator's rotor can be used to provide power for a free electron laser.

\section{POWER SYSTEM COMPONENTS}

To simulate the behavior of proposed systems, it is necessary to assume a notional ship power system. The starting system for this work is shown in Fig. 1. This system does not reflect any known specific application, but it incorporates sufficient complexity that the results should be of interest in a range of applications.

A rail gun launcher provides an excellent opportunity for shared energy storage. A conventional topology for a rail gun power system is shown in Fig. 2. The prime power for the system is provided from the ship's power grid. Conceptually, the drive motor uses the power from the grid to accelerate the rotor, storing the energy in the rotating mass. At this point, the system has the same active components as a flywheel energy storage system that is used to provide backup power to a factory or computer center [3]. By using the rotor of the electromagnetic gun as a flywheel, one can achieve the performance improvements others have proposed using a flywheel [4], [5] without the additional weight and volume of freestanding flywheels. So if the motor is designed properly, the mechanical energy in the spinning rotor can be extracted from the rotor and converted to electricity for such applications as improvement of power quality, ride through power for outages to permit an additional gas turbine to be brought on line, or supplemental power for large pulsed loads.

If the stored energy is used for the rail gun launcher rather than elsewhere in the ship, a capacitor is discharged through the rotor winding. The induced current in the stator is then fed back to the rotor to bootstrap the system to full power. This process typically requires less than $30 \mathrm{~ms}$. When full power is achieved, the alternator is discharged into the rail launcher. The electrical energy stored in the barrel when the projectile leaves is then recovered and used to increase the rotational velocity of the rotor.

The main constituents of the ship power system model, which was developed from the assumed circuit in Fig. 1, include a prime mover block with four gas turbines and four generators, a switchboard block with breakers and power transfer switches, two propulsion power train blocks, each containing a transformer, a rectifier, a PWM motor drive, a propulsion motor, and a service load block with eight different loads 
representing typical ship service loads. The present configuration of the power system model also includes an Electromagnetic Launcher (EML) model and a freeelectron laser (FEL) model. A goal of this study was to show the FEL can operate without draining the main power source by using the energy stored in the EML. The energy stored in the EML system chosen for this study is sufficient to allow the FEL to fire about six to seven pulses without recharging. This operating scheme allows the sharing and transferring of power between the EML and FEL.

The EML model power system is a flywheel-based energy system that stores 800 MJ in eight machine sets. Each set stores $100 \mathrm{MJ}$ and consists of a rectifier, a 5 MVA motor drive, a 5 MW

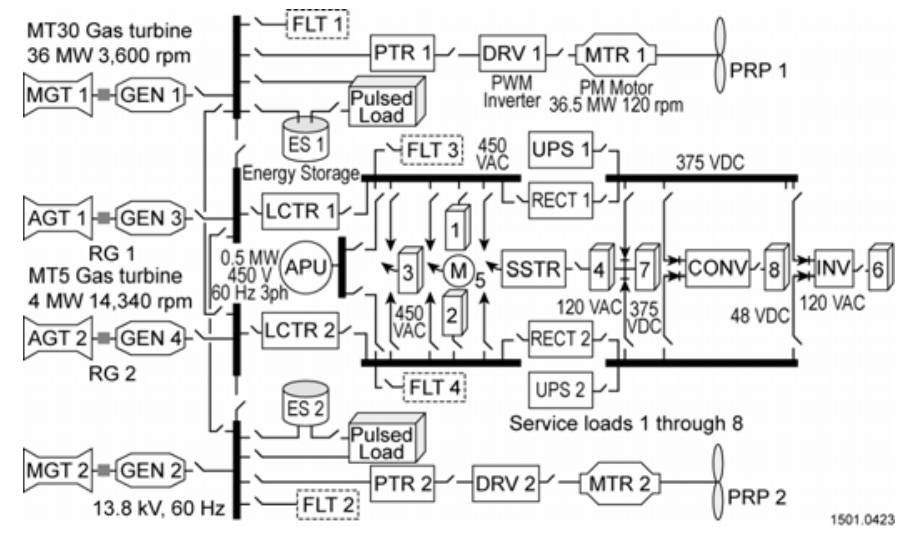

Fig. 1. Notional power system for future electric ship.

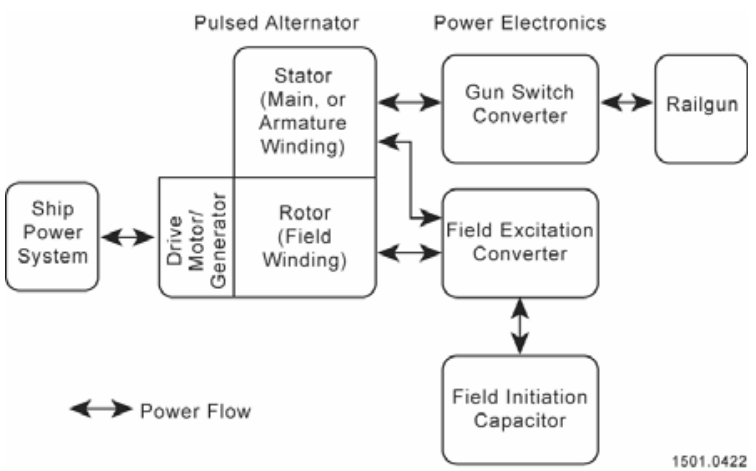

Fig. 2. Block diagram of rail gun power system. high-speed permanentmagnet charging motor/generator, a 2.2 GVA alternator modeled as a wound-field synchronous generator, a rectifier, and a power switch. Fig. 3 shows top-level descriptions of the EML model. For this analysis, the component models were simplified whenever possible to allow practical execution times. The EML system stores five shots with each shot using $160 \mathrm{MJ}$ extracted equally from each of the eight flywheel systems.

\section{SIMULATION ENVIRONMENT}

Three simulation environments, one specially constructed for naval applications and two commercial systems, were tested to determine their suitability for this application. While all three were acceptable, all had difficulty due to the complexity of the system and the widely differing times for relevant responses of the various components. The naval system evaluated was the Virtual Test Bed [6]. The two commercial codes were Acsl and Matlab/Simulink ${ }^{\circledR}$. These proved to have little difference in execution time or in ease of use for this particular application. Matlab/Simulink ${ }^{\circledR}$ was selected for the task. 


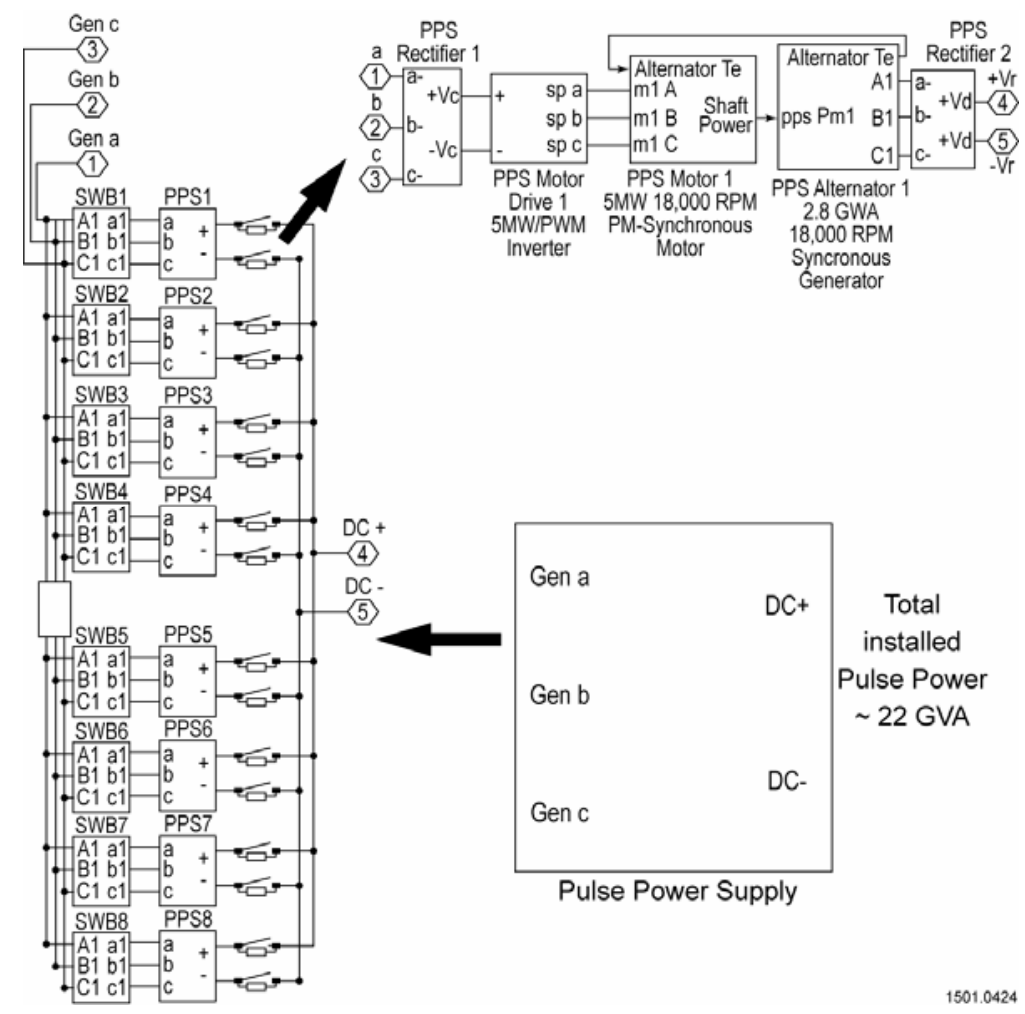

Fig. 3. Circuit model of a ship power system with pulsed load.

\section{Simulation RESUlts}

The size of the electrical energy storage system is set by the power demand of the rail launcher. In this study, it is assumed that the rail launcher provides $64 \mathrm{MJ}$ of kinetic energy to the launched projectile and that the efficiency between the energy stored and the energy of the projectile is $40 \%$. Within limits, the efficiency of the pulsed alternator is a design parameter. In some applications, the size and weight of the alternator must be as small as possible, leading to efficiencies of $20 \%$ or less. For shipboard applications, $40 \%$ efficiency is a convenient level, as it yields a system that is much smaller than the gun and magazine it replaces, and much smaller than a similar energy capacitor power supply. It is further assumed that the EML pulse length is about $9 \mathrm{~ms}$ and that there are $5 \mathrm{~s}$ between consecutive shots. With these assumptions, it is necessary to store $160 \mathrm{MJ}$ and recharge in about $4 \mathrm{~s}$ for each shot in a continuous fire mode.

A Simulink ${ }^{\circledR}$ model of the EML power supply was developed. The power supply was sized for projectiles with $64 \mathrm{MJ}$ muzzle energy, 12 round/minute shot rate, and five shots stored in the kinetic energy of the rotors. It consists of eight high-speed pulsed alternator sets. Fig. 4 shows the response of the bus voltage to an emergency charge, i.e., all units are connected to the power system simultaneously and charged as rapidly as possible. This simulation suggests that, while uncontrolled rapid charging of the system could distort the power grid for a few cycles, the discharge has no effect. It is also quite likely the charging effects can be mitigated by better power management. 
The intermittent nature of high power pulse loads onboard future naval vessels makes the pulse power supply a highly inefficient subsystem, in terms of power density, if it is used solely for its primary purpose. To enhance its functionality, this research explored the use of the energy stored in the rotors of an electromagnetic gun power supply, and its power electronics, as an active filter to reduce harmonic pollution generated by various power conditioning equipment.

To demonstrate the feasibility of this dual-function, a Simulink ${ }^{\circledR}$ model of a propulsion power train, with an integrated pulse power supply and active filter, was developed. Fig. 5 shows the top level model where, for simplicity, only a single propulsion power train and a single $36 \mathrm{MW}$

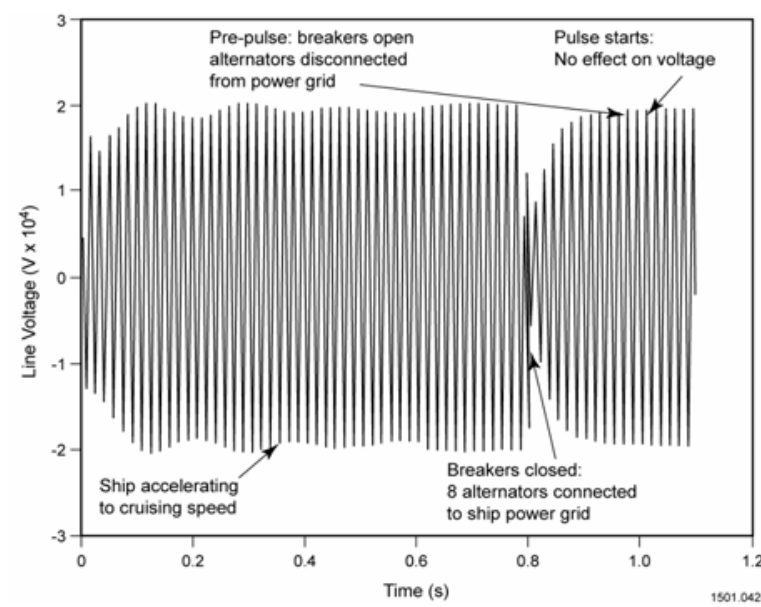

Fig. 4. Maximum effect of charging of electric gun system and gun firing on a ship's bus voltage. (It is a maximum in the sense that no efforts in power management were made.) generator were used. The energy storage block and an inverter were explicitly extracted out of the pulse power supply to clearly show their dual use.

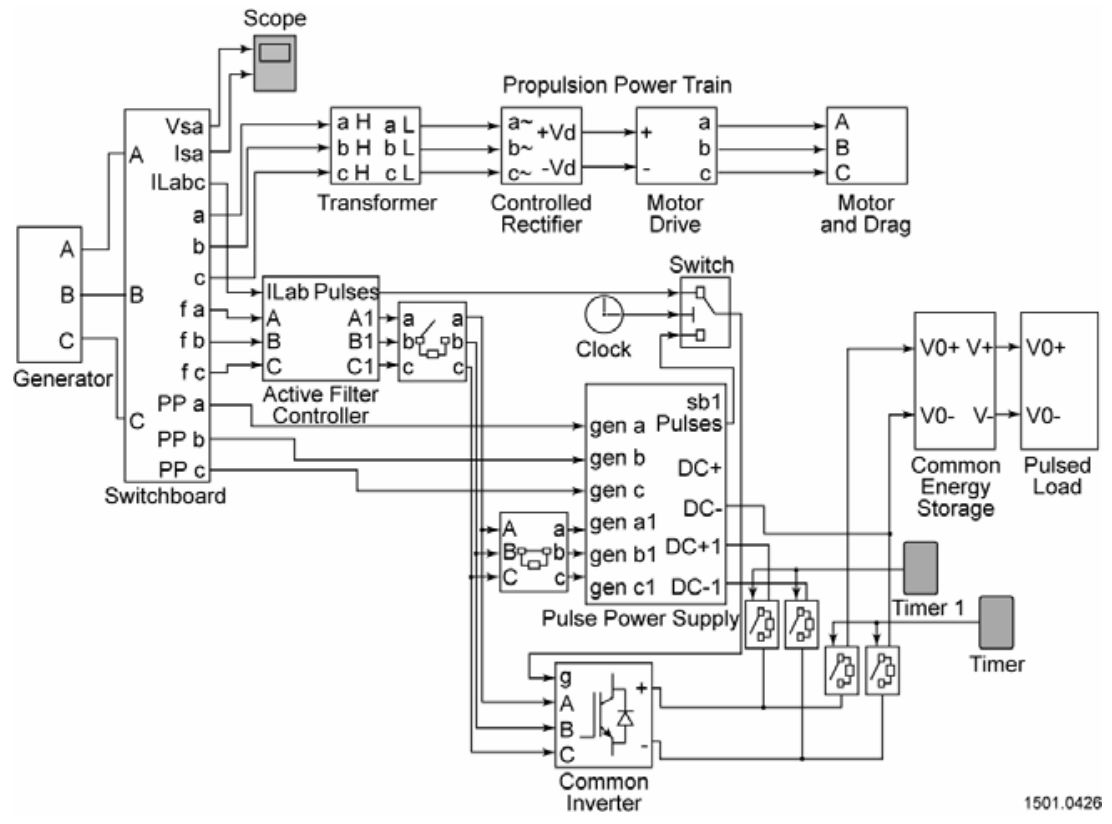

Fig. 5. Circuit model for active filtering.

The active filter works by injecting current into the distribution lines to eliminate harmonic currents or reduce their detrimental effects on sensitive loads. This investigation broadens and reinforces earlier work on the use of flywheel energy storage for voltage sag correction on electric ships [7]. The energy storage components are the 
rotors of the EM rail gun power supply, as mentioned earlier, and the dc link capacitors to which they are connected. The control block consists of a calculation block, a hysteresis control block, and an LC filter to reduce inverter switching harmonics.

When separate energy storage elements and inverters are used in the model, i.e., filter and pulse power supply components are independent, the simulation runs relatively well given the complexity of the model. In this example, the propulsion power train is consuming $\sim 11 \mathrm{MW}$ to keep the ship moving at a cruising speed of 20 knots.

Results are shown in Figs. 6 and 7, where the total harmonic distortion in the voltage and current is reduced from $6.7 \%$ to $4.2 \%$ and from $28.5 \%$ to $8.2 \%$, respectively. While the voltage and current signals are improved, the filtering is not perfect because, in part, the filter parameters are not optimized. Also, the high frequencies in the signals result from using only a single inverter, thereby requiring high switching frequencies $(>30 \mathrm{kHz}$ ). Using additional inverters, from the eight available, should reduce the required switching frequency considerably and further improve signal quality.

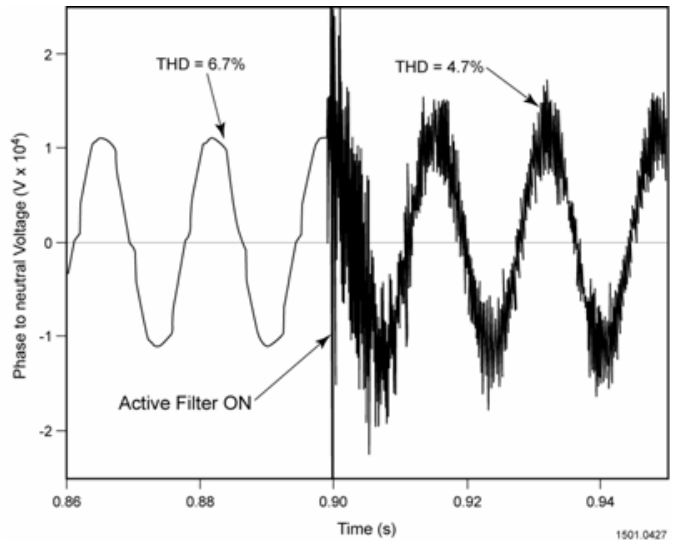

Fig. 6. Voltage with and without active filtering.

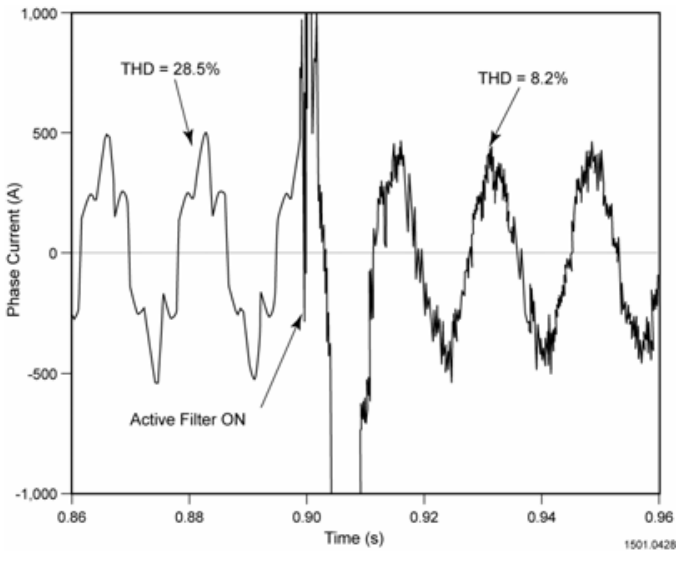

Fig. 7. Current with and without active filtering.

As an example of sharing power among high power loads, the following scenario was assumed: 1) accelerate the ship from rest to full speed, 2) reduce the ship speed to reserve power for charging the EML energy storage system, 3) charge the EML, 4) fire an EML shot and, 5) without recharging, fire four FEL shots using the remaining stored energy. The ship also accelerates to full speed during the FEL pulse firing sequence. This mimics an operational scenario in which the ship is providing over-the-horizon support to troops on shore and is subjected to a missile attack and was selected as a highly stressing, potential operational scenario.

The model is summarized in Fig. 8. In this simulation, power is brought on line by powering the gas turbine. The turbine controllers are set to maintain the generators' speeds constant within the turbine power rating limits. To simplify the computation without sacrificing realism, this step is simulated with the propulsion power trains, ship service loads, and EML/FEL loads off. The reason for this assumption is that gas 
turbines take a long time to reach operating speed compared to other time constants in the electrical circuit. If one assumed that all of the other components were energized as the generators came up to speed, the very fast response of components like inverters would make computational time exceedingly long. Moreover, in practice, generators are generally brought up to operating speed under no-load conditions. Once the gas turbines and generators are turned on, their final states are saved and those states are used in subsequent runs as initial conditions.

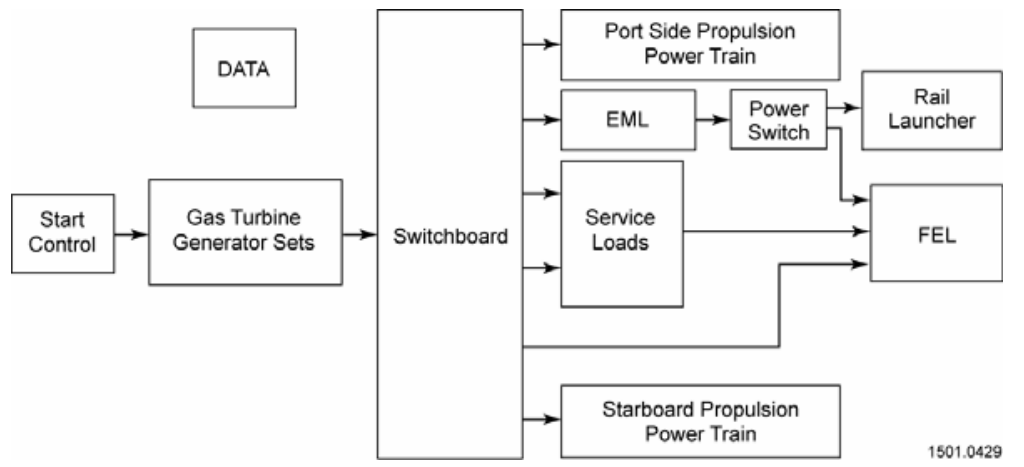

Fig. 8. Top-level Matlab/Simulink ${ }^{\circledR}$ model of the electric ship power system.

The top-level model of the power system for the electromagnetic launch system is shown in Fig. 9. Each of the primary blocks represents the pulsed alternator and power electronics systems shown in Fig. 2. The stored energy can be extracted at a level of 5 MW per unit using the drive motor/generator.

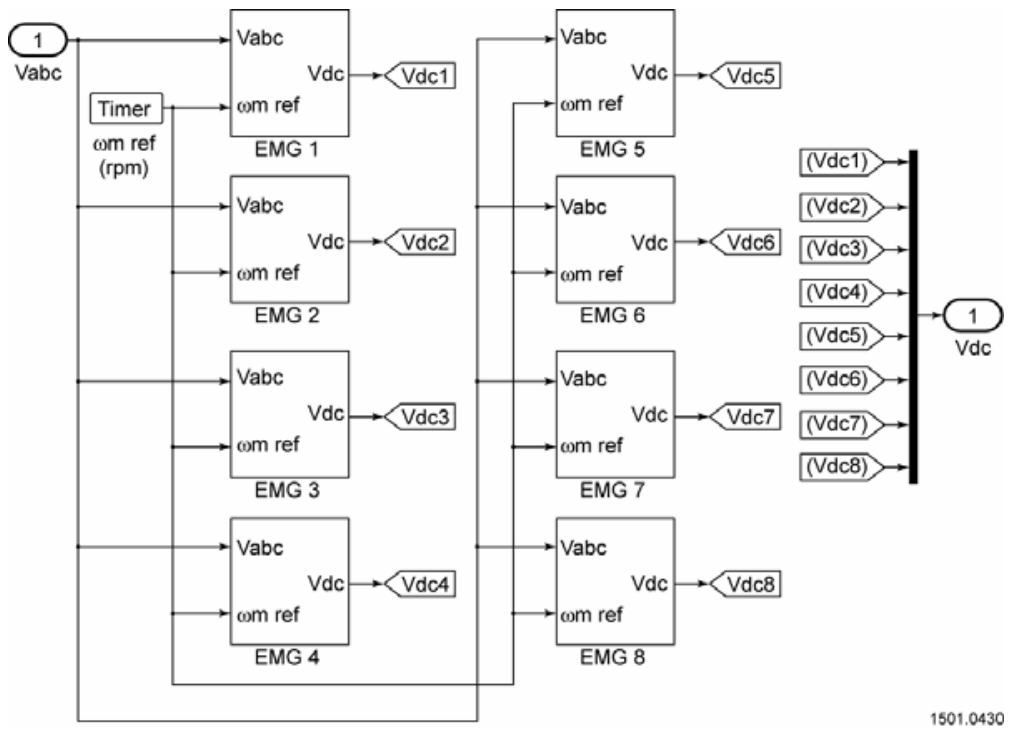

Fig. 9. Top-level Matlab/Simulink ${ }^{\circledR}$ model of the electromagnetic launch power system shown functionally in Fig. 2.

Within each of the key blocks in Fig. 9, the alternator and power electronics are represented by four blocks, as shown in Fig. 10. The block labeled "Charging Motor" contains the model for the $5 \mathrm{MW}$ motor/generator that is used to store energy in the flywheel or extract energy at the $5 \mathrm{MW}$ rate. The "Dynamics" block contains a model that represents the flywheel dynamics. When a capacitor is discharged into the winding 
on the spinning flywheel, the flywheel becomes the rotor of a pulsed alternator. The alternator performance is captured in the "Alternator" block. Finally, the multiphase ac signal produced by the alternator is transmitted to the "RG Rectifier" block which delivers a unipolar GW-level pulse to the rails.

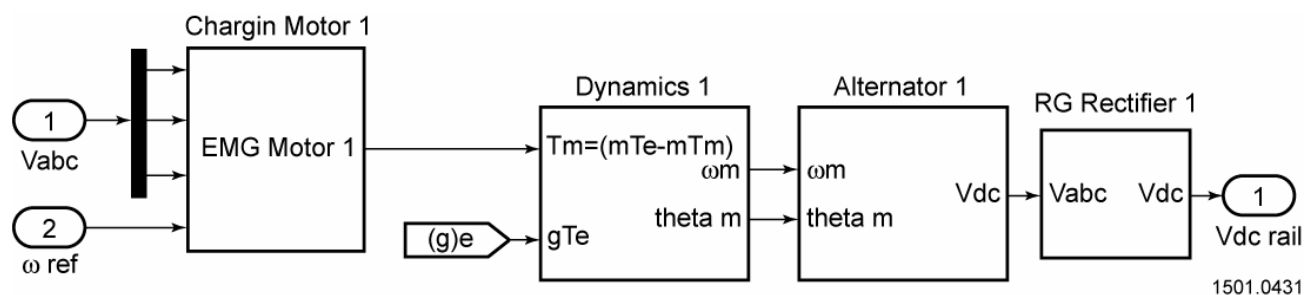

Fig. 10. Functional components of each of the eight flywheel energy storage systems.

The FEL system model (Fig. 8) was also simplified. It was designed to appropriately represent the power level and width of each pulse as well as take into account the power needed by the auxiliary equipment necessary for FEL operation. Continuous and intermittent ac and dc power was used during the firing cycle. The bulk of the FEL power consists of $20 \mathrm{MW}, 5 \mathrm{~s}$ long pulses. Four pulses, spaced by $2 \mathrm{~s}$ intervals, were simulated. Because the railgun power supply was designed to store five launches in the rotor with $160 \mathrm{MJ} /$ launch and launches spaced $5 \mathrm{~s}$ apart, it also appears to be an attractive source for a free electron laser requiring storage of $100 \mathrm{MJ}$ shots, $2 \mathrm{~s}$ apart. In practice, the time between the pulses may be longer due to cooling and other operating constraints, but using the short time interval between shots saves simulation time and provides a more challenging load to the power system. While the FEL is also capable of being powered from the main switchboard, that mode was not explored in this investigation.

The energy used by the FEL during the firing cycle is shown in Fig. 11, along with the rotor speed profile. This figure shows that even after one electromagnetic launch and four discharges of the free electron laser, the rotor retains more than $50 \%$ of its initial speed. In addition, the time interval between the electromagnetic launch and the fourth laser pulse is only about $30 \mathrm{~s}$. Fig. 12 shows another view of the same information. Whereas Fig. 11 shows the rotor speed during the firing sequence, Fig. 12 shows the remaining energy.

Fig. 13 shows the power generated by the pulsed alternator and the power consumed by the rail launcher. The discharge time for the rail launcher is about $10 \mathrm{~ms}$. The power oscillations during the launch are likely unacceptable in a practical system and can be minimized using a somewhat more complex model. They were viewed as insignificant, however, for the purposes of this investigation. Similarly, the large power spike at launch would be eliminated using an appropriate muzzle shunt. Since the energy represented by this pulse is small and accurate representation of the launch requires detailed lengthy calculations on times short compared to a millisecond, it was assumed that accurate modeling of this transition would require excessive computation time while providing minimal improvement in the simulation results.

Finally, the overall power used during the prescribed scenario is shown in Fig.14. As shown on the graph, the acceleration time is artificially short ( $10 \mathrm{~s})$ as nothing of 
interest is happening in the power system during the ship acceleration time. This is a computational convenience, not an assertion that accelerating an electric ship from standstill to 30 knots is possible in $10 \mathrm{~s}$. The ship speed is then reduced to its cruising speed of 20 knots. When the cruising speed is reached, the flywheels are charged as rapidly as possible. If the cruising speed were higher, the charge time would have to be longer. The charged flywheels can maintain full charge for an arbitrarily long time with trickle charge, compared to the $80 \mathrm{MW}$ of total charging power, to overcome losses. The simulations show that, if necessary, the electromagnetic launcher and free electron laser could both be used, using the stored energy, while using the full generator power to accelerate the ship.

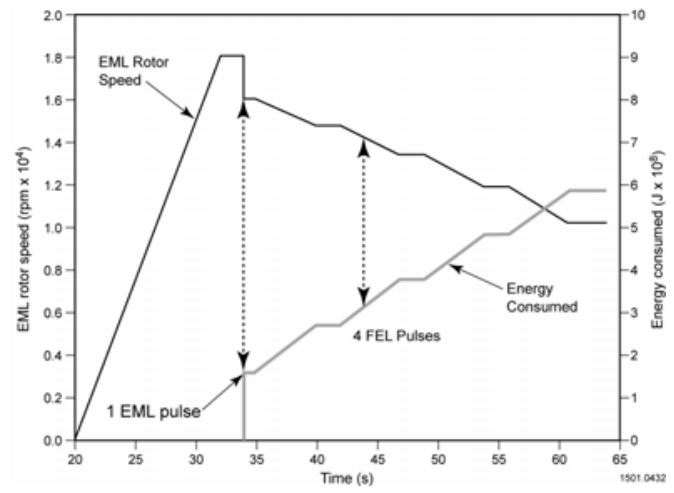

Fig. 11. Energy consumed during EML and FEL pulses and corresponding rotor speeds.

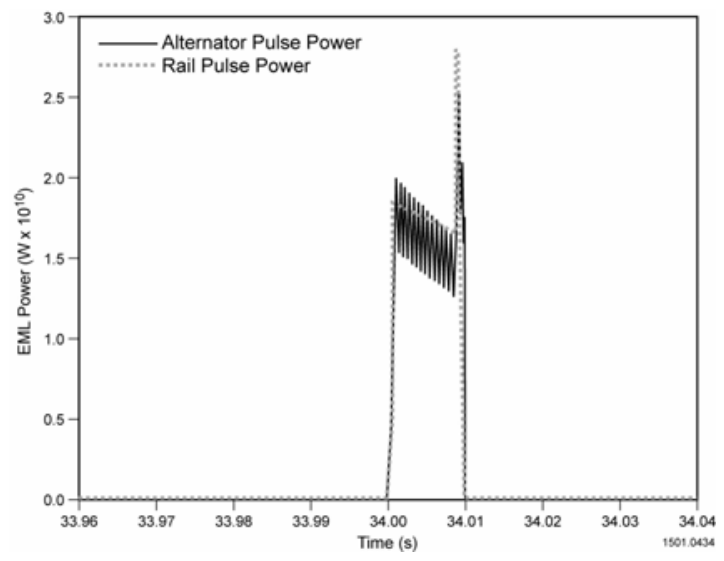

Fig. 13. Alternator and rail launcher power during pulse.

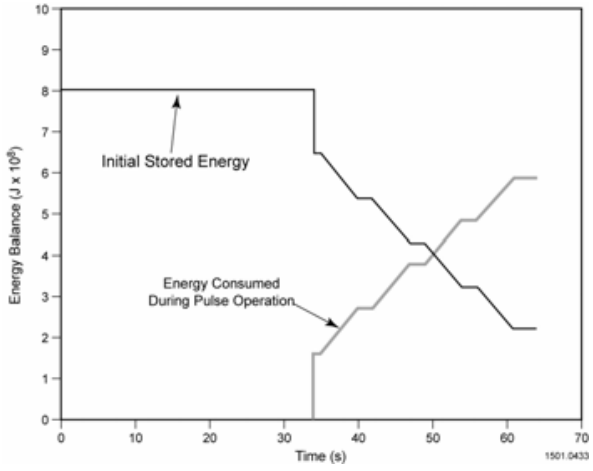

Fig. 12. Energy balance during the pulse firing sequence.

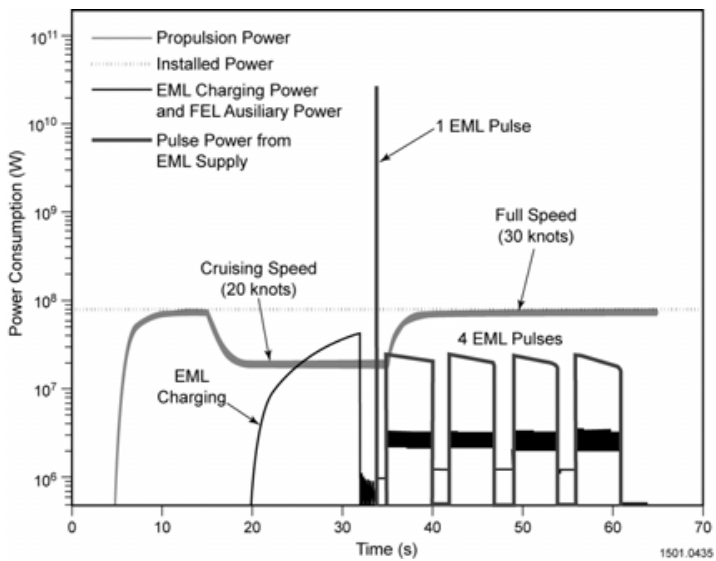

Fig. 14. Power consumed during the

IML/FEL operation while the ship is in motion.

The scenario shown in Fig. 14 obviously is not unique. If one wished to recharge the energy storage system, one could delay accelerating the ship for somewhat less than $10 \mathrm{~s}$ after the shots were made. To fully charge the EML system (800 MJ), about 20 seconds are needed. This is determined by both the available power from the ship grid and the rating of the charging motors. To reduce simulation time, as was the case for the ship acceleration time, the charging time, as shown in Fig. 9, was reduced to 14 seconds. The charging was done while the ship was cruising at 20 knots to ensure that $40 \mathrm{MW}$ were available at the ship power grid. Since the system is still charged at about $25 \%$ of its peak energy after this shot sequence, the recharge time can be shorter. 


\section{CONCLUSIONS}

From an energy perspective, it is reasonable to assume a free electron laser and a rail launcher can coexist effectively on a future electric ship. This work uses models of an electric ship power system, an electromagnetic launcher power system, and a free electron laser power system to simulate an operational scenario that shows how systems can be configured so that these components can share capability and be used effectively. The current work showed that making the stored energy for the electromagnetic launcher available to both the launcher and to the main power bus allows the flexibility to handle at least one important load, the free electron laser. This approach permits short term operation at power levels higher than can be produced continuously by the ship's power system.

This investigation shows an effective approach to performing such simulations. While more detailed work is possible, it is unlikely it will be necessary until the ship's power system is defined. The current level of detail is sufficient to give insight into the general operational characteristics that are available and provides guidance for those making power system design decisions.

\section{Acknowledgment}

This investigation was funded by the Office of Naval Research.

\section{References}

[1] R. Hebner, et al., "An electromagnetic gun power supply as a component of an electric ship power system,” ASNE High Powered Weapons Systems for Electric Ships, Annapolis, Maryland, U.S.A., December 7-9, 2004.

[2] J. Beno, A. Ouroua, and M. Flynn, "Effects of EM weapons requirements on the electric ship power system,” IMAREST Engine as a Weapon Symposium, Bristol, UK, June 9-10, 2004.

[3] R. Hebner, J. Beno, and A. Walls, “Flywheel batteries come around again,” IEEE Spectrum, vol. 39, April 2002, pp. 46-51.

[4] J. McGroarty, J. Schmeller, R. Hockney, and M. Polimeno, "Flywheel energy storage system for electric start and an all-electric ship," Proceedings, 2005 IEEE Electric Ship Technologies Symposium, Philadelphia, Pennsylvania, U.S.A., July 25-27, 2005, pp. 400-406.

[5] H. A. Toliyat, S. Talebi, P. McMullen, H. Co, and A. Filatov, “Advanced high-speed flywheel energy storage systems for pulsed power applications,” Proceedings, 2005 IEEE Electric Ship Technologies Symposium, Philadelphia, Pennsylvania, U.S.A., July 25-27, 2005, pp. 379-386.

[6] L. Cristaldi, A. Ferrero, A. Monti, F. Ponci, W. McKay, and R. Dougal, “A virtual environment for remote testing of complex systems," IEEE Transactions on Instrumentation and Measurement, vol. 54, 2005, pp. 123-133.

[7] S. Samineni, B. K. Johnson, H. L. Hess, and J.D. Law, "Modeling and analysis of a flywheel energy storage system for voltage sag correction,” Proceedings, IEEE International Electric Machines and Drives Conference, June 1-4, 2003, vol. 3, pp. 1813-1818. 